\title{
The relationship between Helicobacter pylori motility, morphology and phase of growth: implications for gastric colonization and pathology
}

\author{
Mulugeta L. Worku, ${ }^{1}$ Ramon L. Sidebotham, ${ }^{1}$ Marjorie M. Walker, ${ }^{2}$ \\ Tajali Keshavarz ${ }^{3}$ and Q. Najma Karim ${ }^{1}$
}

Author for correspondence: Q. Najma Karim. Tel: +44 171725 1074. Fax: +44 1717251856.
e-mail: q.karim@ic.ac.uk

1 Department of Medical Microbiology, Imperial College School of Medicine at St Mary's, Norfolk Place, London W2 1PG, UK

2 Department of Histopathology, Imperial College School of Medicine at St Mary's, Norfolk Place, London W2 1PG, UK

3 Department of Biotechnology, School of Biosciences, University of Westminster, New Cavendish Street, London W1M 8JS, UK

\begin{abstract}
To explore the relationship between Helicobacter pylori motility, morphology and phase of growth, bacteria were isolated from antral biopsies of patients with duodenal ulcer or non-ulcer dyspepsia, and grown in liquid medium in batch and continuous culture systems. Motilities and morphologies of $\boldsymbol{H}$. pylori in different phases of growth were examined with a Hobson BackTracker and by transmission electron microscopy. Morphologies of bacteria grown in vitro were also compared with those of bacteria in antral biopsies from patients with non-autoimmune gastritis. H. pylori had poor motility in lag phase, became highly motile in mid-exponential phase and lost motility in the decline phase of growth. Motilities of bacteria in the same phase of growth from patients with duodenal ulcer or non-ulcer dyspepsia were not significantly different. In the mid/late-exponential phase of growth bacteria had helical morphologies and multiple polar flagella, typical of $\boldsymbol{H}$. pylori in the gastric mucus layer. In the decline phase of growth bacteria shed flagella, and had precoccoidal or coccoidal morphologies. These findings support the view that helical and coccoidal $\boldsymbol{H}$. pylori are in different phases of growth with different roles in gastric colonization, indicate that bacterial motility per se is unlikely to be a determinant of $H$. pylori pathology, and suggest that $H$. pylori in the antral mucus layer is in a state of continuous (exponential phase) growth.
\end{abstract}

Keywords: Helicobacter pylori, bacterial motility, bacterial morphology, growth phase

\section{INTRODUCTION}

Helicobacter pylori is a Gram-negative mucophilic bacterium that colonizes gastric mucosa and damages epithelial cells by association and cytotoxin release (Hessey et al., 1990). As a consequence it is the principal cause of non-autoimmune gastritis and peptic ulcer, and an aetiological factor in gastric carcinoma (Baron, 1993; O’Connor et al., 1996; Nomura et al., 1994).

Bacterial motility is generally held to be a requirement for H. pylori colonization of the stomach (Eaton et al., 1989, 1992). Consistent with this view, the bacteria in vivo typically possess helical morphologies and multiple polar flagella (Hazell et al., 1986). There have, however,

Abbreviations: CLV, curvilinear velocity; PL, path length. been reports of apparently non-motile $H$. pylori with Ushaped, doughnut-shaped (precoccoidal; Benaissa et al., 1996) and coccoidal (Buck et al., 1986; Chan et al., 1994; Janas et al., 1995; Megraud, 1989; Moshkowitz et al., 1994; Noach et al., 1994) morphologies. H. pylori with these atypical structures is seen occasionally in vivo (Caselli et al., 1993; Chan et al., 1994; Janas et al., 1995 ; Noach et al., 1994), but most frequently in vitro in old cultures (Andersen et al., 1997; Catrenich \& Makin, 1991; Cellini et al., 1994; Jones \& Curry, 1990; Kusters et al., 1997; Mai et al., 1989; Moshkowitz et al., 1994; Nilius et al., 1993). It remains uncertain whether coccoidal forms are degenerative (Buck et al., 1986; Catrenich \& Makin, 1991; Cellini et al., 1994; Kusters et al., 1997; Nilius et al., 1993), or adaptations to marginal or hostile environments (Janas et al., 1995), with a capacity for transmission and regrowth to the bacillary form (Andersen et al., 1997; Benaissa et al., 
1996; Bode et al., 1991; Jones \& Curry, 1990; Mai et al., 1989).

In this paper we have examined how $H$. pylori motility is affected by bacterial morphology and phase of growth, with the aim of further clarifying the interrelationship between bacillary and coccoidal forms of the bacterium, and the possible role of motility in gastric colonization and pathology.

\section{METHODS}

Bacteria. Antral biopsies were obtained at endoscopy from 13 patients with duodenal ulcer and 14 patients with non-ulcer dyspepsia. H. pylori was isolated by plating the biopsies on Columbia agar (BBL) with $7 \%$ horse blood (TSCL) made selective by adding $20 \mathrm{mg}$ nalidixic acid $\mathrm{l}^{-1}, 2 \mathrm{mg}$ amphotericin $\mathrm{B}^{-1}$ and $3 \mathrm{mg}$ vancomycin $\mathrm{l}^{-1}$. The plates were then incubated at $37^{\circ} \mathrm{C}$ for $72 \mathrm{~h}$ in a microaerophilic atmosphere generated in a GasPak jar (Oxoid) using a CampyPaks (BBL). Bacterial colonies were finally removed from the plates and stored in $0.5 \mathrm{ml} 15 \%(\mathrm{v} / \mathrm{v})$ sterile glycerol broth at $-80{ }^{\circ} \mathrm{C}$ until required.

Batch culture. Bacteria were thawed at room temperature, plated out on $7 \%(\mathrm{v} / \mathrm{v})$ defibrinated horse blood agar, which included H. pylori selective supplement (Oxoid), and incubated in a microaerophilic atmosphere (see above) at $37^{\circ} \mathrm{C}$ for $48 \mathrm{~h}$. Colonies from these plates were suspended in sterile saline to a turbidity equivalent to that of McFarland's No. 4 standard $\left(10^{8}\right.$ bacteria $\left.\mathrm{ml}^{-1}\right)$. From this suspension, $100 \mu \mathrm{l}$ was transferred to $2.9 \mathrm{ml}$ brain heart infusion broth (BBL) supplemented with $10 \%(\mathrm{v} / \mathrm{v})$ newborn calf serum (Sigma) and $H$. pylori selective supplement. The broth was then incubated with agitation in a $50 \mathrm{ml}$ capacity loose-capped container (Bibby Sterilin) in a microaerophilic atmosphere $\left(10 \% \mathrm{CO}_{2}\right.$, $18 \% \mathrm{O}_{2}$ and $72 \% \mathrm{~N}_{2}$ ) at $37{ }^{\circ} \mathrm{C}$ for at least $72 \mathrm{~h}$. Aliquots (totalling $200 \mu \mathrm{l}$ ) were withdrawn periodically for assessment of bacterial motility, and viable count by the method of Miles and Misra as modified by Miles et al. (1938). Gram stain, oxidase and catalase tests were used to confirm absence of contamination.

Continuous culture. Bacteria were grown under conditions comparable to those reported by Hudson \& Newell (1989). The chemostat apparatus used was a series 00II modular fermenter (LH Fermenters), fitted with 11 capacity glass culture vessel and autoclavable plate and fittings of nylon and silicon rubber. The top plate had ports for redox and $\mathrm{pH}$ electrodes, a thermocouple, and gas, growth medium and sampling lines.

Growth medium (broth $\mathrm{pH} 7$; made H. pylori-selective as described above) was introduced into the culture vessel by continuous pumping through anti-growback glass tubing, and the volume of fluid was maintained at $600 \mathrm{ml}$ by an overflow tube. The growth medium was maintained at $37^{\circ} \mathrm{C}$ by external heating, stirred at 150-200 r.p.m. and sparged with a $5 \% \mathrm{O}_{2}$, $10 \% \mathrm{CO}_{2}$ and $85 \% \mathrm{~N}_{2}$ gas mixture.

The culture vessel was inoculated with $30 \mathrm{ml} \mathrm{H}$. pylori (in exponential phase of growth) in selective broth at a concentration of $10^{8}$ bacteria $\mathrm{ml}^{-1}$. When bacteria had attained exponential growth, fresh medium was pumped into the culture vessel at a dilution rate of 0.05 culture volumes $\mathrm{h}^{-1}(D$ $=0 \cdot 12 \mathrm{~h}^{-1}$ ) and growth was monitored for $14 \mathrm{~d}$ thereafter by on-line measurements of $\mathrm{OD}_{550}$ with a Perkin Elmer spectro- photometer against a blank of fresh medium. Aliquots $(5 \mathrm{ml})$ were removed at 6 hourly intervals for assessment of bacterial motility.

Motility measurements. Aliquots $(10 \mu \mathrm{l})$ of the culture broth (prediluted when necessary with fresh medium to a concentration not exceeding $10^{7}$ bacteria $\mathrm{ml}^{-1}$ ) were added to saline $(90 \mu \mathrm{l})$, and the resulting bacterial suspension $(\mathrm{pH} 7)$ was drawn by capillary action into an optical microslide (Camlab) of $0 \cdot 1 \mathrm{~mm}$ path length. The microslide was sealed at one end with vinyl plastic putty (Oxford; Labware), transferred to the warm stage $\left(37^{\circ} \mathrm{C}\right)$ of a phase-contrast microscope at $\times 40$ magnification, and allowed to equilibrate $(5 \mathrm{~min})$ before observations were commenced with a Hobson BacTracker. To ascertain the contribution of Brownian movement to bacterial motility, H. pylori was killed by exposure to $10 \%(\mathrm{v} / \mathrm{v})$ formalin for $10 \mathrm{~min}$ at room temperature, before examination with the Hobson BacTracker.

The Hobson BacTracker, a new 'blob and track' imageprocessing technology developed by Hobson Tracking Systems, Sheffield, UK, permits bacterial motility to be quantitatively measured in real time. In this system the microscopic image of the bacteria is recorded by video camera, and displayed on the tracker screen. Movements of up to 120 bacteria may be simultaneously and continuously monitored, with results reported in either histogram or trail draw formats. The Hobson system has the potential to examine 10 parameters of bacterial motility. Two representative parameters were used to assess the motilities of H. pylori in this study: curvilinear velocity (CLV; the distance in $\mu \mathrm{m}$ travelled along the path of the bacterium in each second between two stops) and path length (PL; the distance in $\mu \mathrm{m}$ travelled by the bacterium between two stops). Data collected by the BacTracker were analysed by the Mann-Whitney Utest with an SPSS (Social Sciences Version 6) statistics package. A detailed description of the Hobson BacTracker and its operation may be found in the manufacturer's literature.

\section{Transmission electron microscopy}

Bacteria in culture. H. pylori in lag, exponential and decline phases of growth was prepared for negative contrast transmission electron microscopy as described by Haschemyer \& Meyers (1972). Bacteria were transferred to a 400-mesh carbon-coated copper grid by floating the grid, coated side down, on a drop of $H$. pylori culture fluid for about 2 min. Excess liquid was removed by touching the grid with a filter paper, and bacteria were then negatively stained by floating the grid on a drop of $2 \%(\mathrm{w} / \mathrm{v})$ phosphotungstic acid solution ( $\mathrm{pH}$ 6.5) for $1 \mathrm{~min}$. Excess liquid was again removed by touching the grid with a filter paper, and the bacterial preparation was examined with a Philips EM 400 transmission electron microscope.

Bacteria in antral biopsies. Antral biopsies from patients with $H$. pylori-associated non-autoimmune gastritis and functional dyspepsia were fixed for $2 \mathrm{~h}$ in $4 \%(\mathrm{w} / \mathrm{v})$ glutaraldehyde. The tissue was then post-fixed in osmium tetroxide, stained with uranyl acetate, dehydrated through an ethyl alcohol sequence until the alcohol content reached $100 \%$ and embedded in Taab 812 resin. Sections $(0.5 \mu \mathrm{m})$ were initially cut for explorative light microscopy. Ultra-thin sections (approx. $100 \mathrm{~nm}$ ) were then cut with a diamond knife from relevant blocks, collected on copper grids and stained with Reynolds lead stain, before examination with a Philips EM 400 transmission electron microscope. 


\section{RESULTS}

\section{Growth of $\boldsymbol{H}$. pylori in batch culture}

Preliminary experiments (data not included) conducted with residual biopsies revealed that they provide very low inocula, so that broth cultures could take between 6 and $9 \mathrm{~d}$ to attain exponential phase of growth. As a result, suspensions from agar plates containing $10^{7}-10^{8}$ bacteria $\mathrm{ml}^{-1}$ were used to inoculate batch cultures in the present study. Growth curves were highly reproducible with these consistent and heavy inocula, with bacteria entering the exponential phase of growth within $24 \mathrm{~h}$ and stationary phase $1 \mathrm{~d}$ later. The mean results for four different isolates are given in Fig. 1(a). Our findings are compatible with those reported by Xia et al. (1993).
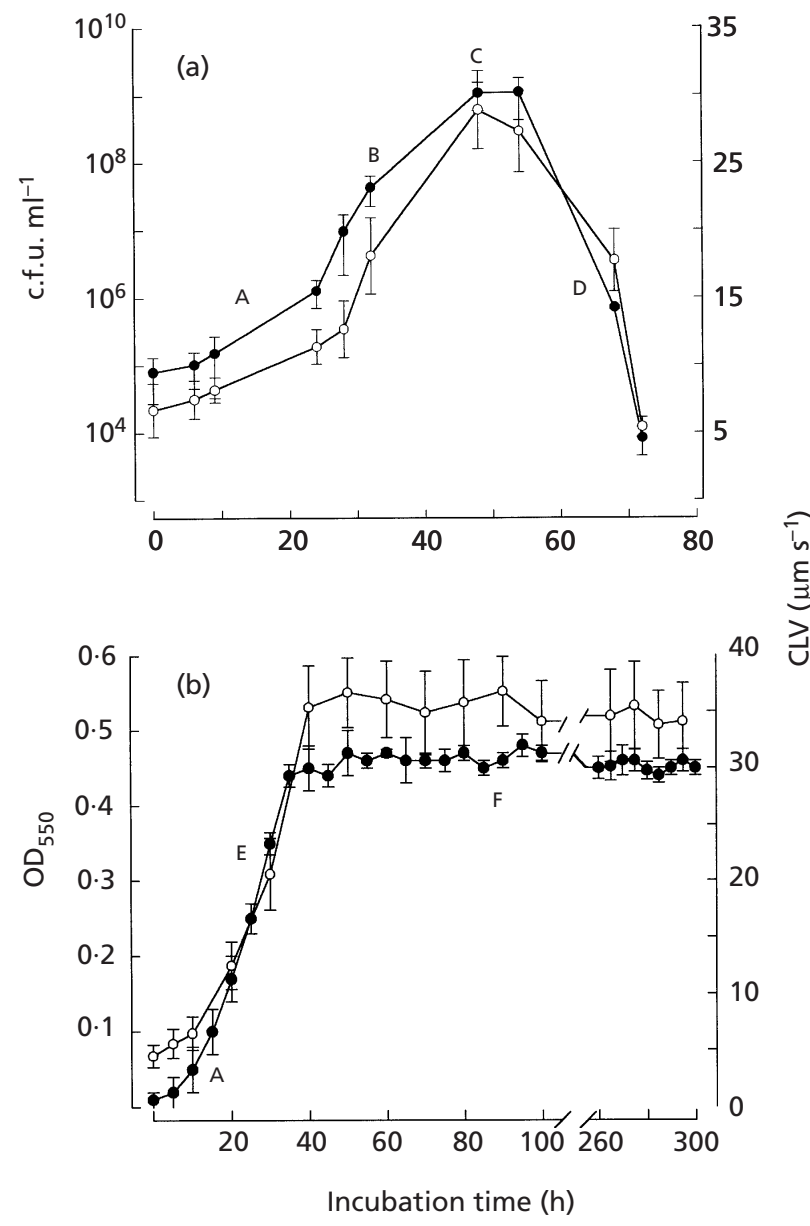

Fig. 1. Influence of growth phase on motility of $H$. pylori in batch (a) and continuous (b) culture systems. The curves represent the combined data from four (batch culture) and three (continuous culture) isolates. Data are from bacteria in lag phase (A), exponential phase (B), stationary phase $(C)$ and decline phase (D) of growth. Also shown are bacteria in the exponential phase of growth before fresh medium was allowed to flow into the culture vessel (E), and under continuous culture conditions (F) at a dilution rate of 0.05 culture volumes $\mathrm{h}^{-1}$. Bacterial motility $(O)$ is expressed as $\operatorname{CLV}\left(\mu \mathrm{m} \mathrm{s}^{-1}\right)$, and bacterial density (O) in c.f.u. $\mathrm{ml}^{-1}$, or as $\mathrm{OD}_{550}$.
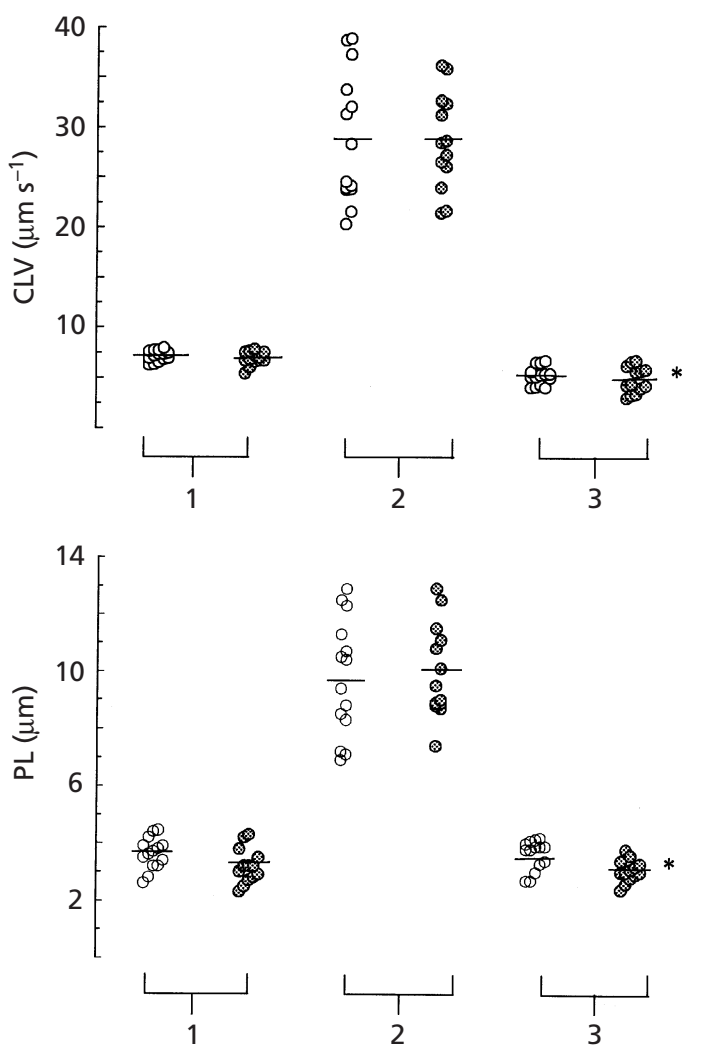

Fig. 2. $\mathrm{CLV}$ and $\mathrm{PL}$ of $H$. pylori in batch culture in different phases of growth: (1) about $10 \mathrm{~h}$ after inoculation (lag phase); (2) about $15 \mathrm{~h}$ after bacteria entered exponential phase (mid/late-exponential phase); (3) about $20 \mathrm{~h}$ after bacteria entered stationary phase (late-decline phase). Bacteria in $\mathrm{mid} /$ late-exponential phase of growth had significantly $(P$ $<0.001)$ greater CLV and PL than bacteria in lag or decline phases of growth. Motilities of $H$. pylori isolated from patients with duodenal ulcer $(\otimes)$ and non-ulcer dyspepsia $(O)$ were not significantly different. *, Brownian movement.

\section{Growth of $\boldsymbol{H}$. pylori in continuous culture}

Experiments were initially conducted to establish a dilution rate that would maintain the bacteria in a state of continuous growth. Three different isolates of $H$. pylori were then examined in the continuous culture system for a period of $14 \mathrm{~d}$. The mean results are given in Fig. 1(b). After inoculation into the chemostat vessel $H$. pylori remained in the lag phase of growth for a mean of $14 \mathrm{~h}$. Thereafter, the optical density of the culture increased exponentially, as bacteria entered exponential phase of growth, to attain a maximum $\left(\mathrm{OD}_{550} 0.48\right)$ within $35 \mathrm{~h}$. The optical density decreased transitorily (to $\mathrm{OD}_{550} 0 \cdot 44$ ) when fresh medium was initially allowed to flow into the culture vessel, then recovered, and remained at a high level $\left(\mathrm{OD}_{550} 0.48 \pm 0.05\right)$ for the duration of the experiment. The $\mathrm{pH}$ of the growth medium remained unchanged throughout the experiment. The dilution rate used in our growth experiments $\left(0 \cdot 05\right.$ culture volume $\left.\mathrm{h}^{-1}\right)$ compared favourably with dilution rates $\left(0 \cdot 05-0 \cdot 2\right.$ culture volume $\left.\mathrm{h}^{-1}\right)$ reported by Hudson \& Newell (1989) for optimal chemostat growth 


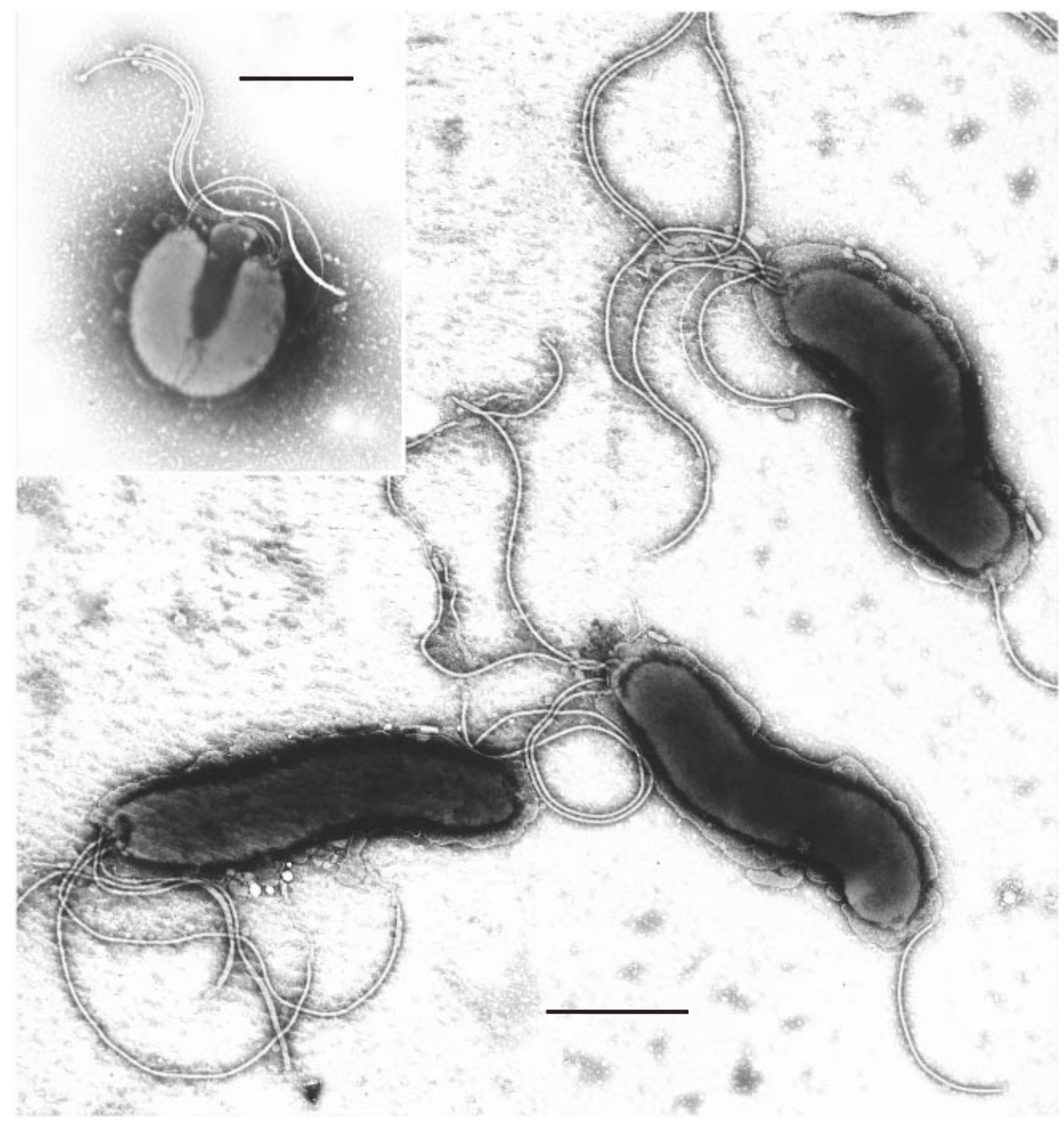

Fig. 3. Electron micrographs of negatively stained preparations of $H$. pylori in lag and exponential phases of growth, illustrating non-dividing bacteria with helical forms and multiple polar flagella, and (inset; top) a bacterium in division with clearly visible division septum and bunches of flagellar filaments at each pole. Bars, $500 \mathrm{~nm}$.

of $H$. pylori in plasma-supplemented brucella broth $(\mathrm{pH}$ 7) at $37^{\circ} \mathrm{C}$.

\section{Motilities of $\boldsymbol{H}$. pylori in different phases of growth}

Two parameters were used to quantify the (translational) motions of the bacteria: CLV and PL.

The change in mean $H$. pylori motility throughout the growth cycle in batch culture is shown in Fig. 1(a). The curve demonstrates that CLV is closely linked with bacterial growth in lag and exponential phases of growth, then decreases sharply shortly after bacteria enter the stationary phase of growth.

Translational motions of $H$. pylori from a larger number of isolates were examined at selected points on batch growth curves, to ascertain whether motilities of bacteria from patients with duodenal ulcer and non-ulcer dyspepsia were significantly different. Results are summarized in Fig. 2. All the bacteria were essentially non-motile in the early-lag phase of growth (mean CLV was $7 \cdot 0$, SD $5 \cdot 7 \mu \mathrm{m} \mathrm{s}^{-1}$; mean PL was $3 \cdot 8 \pm 3 \cdot 1 \mu \mathrm{m}$ ), became highly motile in late-exponential and earlystationary phases of growth (mean CLV was $28 \cdot 7 \pm 5.6 \mu \mathrm{m} \mathrm{s}^{-1}$; mean PL was $\left.9 \cdot 9 \pm 1.8 \mu \mathrm{m}\right)$, and lost motility in the late-decline phase of growth (mean CLV was $5 \cdot 0 \pm 1 \cdot 0 \mu \mathrm{m} \mathrm{s}^{-1}$; mean PL was $3 \cdot 1 \pm 0 \cdot 3 \mu \mathrm{m}$ ).

$H$. pylori was essentially non-motile in the initial lag phase of growth (mean CLV was $4.5 \pm 1 \mu \mathrm{m} \mathrm{s}^{-1}$ and mean PL was $1.4 \pm 0.4 \mu \mathrm{m} 12 \mathrm{~h}$ after inoculation) in the continuous culture system (Fig. 1b). Motility then increased exponentially as the bacteria entered 


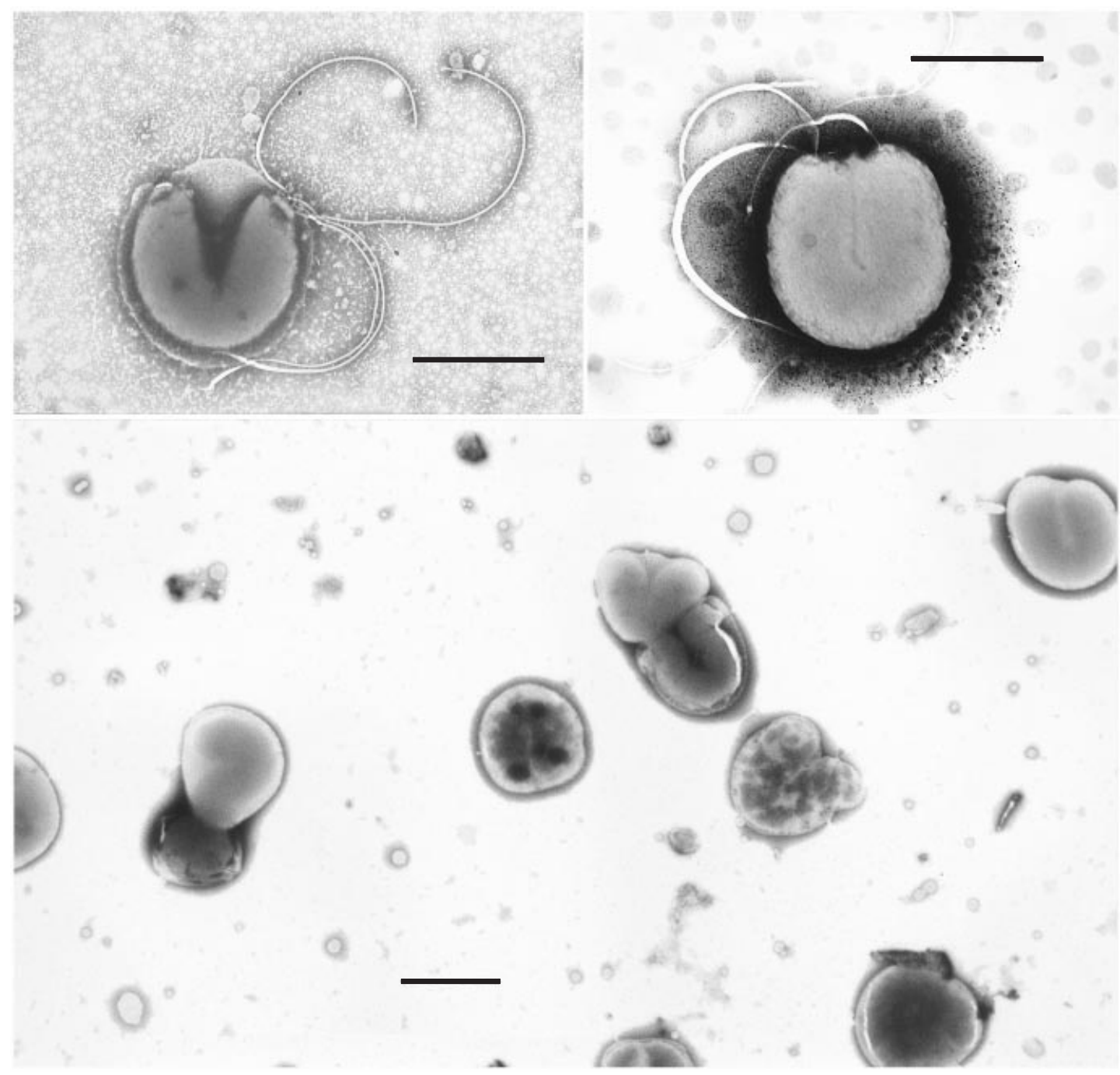

Fig. 4. Electron micrographs of negatively stained preparations of $H$. pylori in the decline phase of growth, illustrating early (top left) and late (top right) stages in the genesis of coccoidal forms (bottom) of the bacterium. Precoccoidal forms (top left; top right) typically carry flagellar filaments on a single pole, which are lost from coccoidal forms. Bars, $500 \mathrm{~nm}$.

the exponential phase of growth (mean CLV was $32 \pm 4 \cdot 1 \mu \mathrm{m} \mathrm{s}^{-1}$ and mean PL was $14 \pm 4 \cdot 3 \mu \mathrm{m} 36 \mathrm{~h}$ after inoculation), and remained at a high level throughout the duration of the experiment. The highest motility attained by $H$. pylori in continuous culture was comparable to that attained by the bacterium in batch culture when in late-exponential and early-stationary phases of growth.

\section{Morphologies of $\boldsymbol{H}$. pylori in different phases of growth}

Morphologies of H. pylori in lag and exponential phases of growth are shown in Fig. 3, and in the decline phase of growth in Fig. 4. Bacteria in lag and exponential phases of growth were morphologically indistinguishable. The populations were composed predominantly of non-dividing bacilli (about $85 \%$ in lag phase, decreasing to about $60 \%$ in early-exponential phase, as judged from a small number of photomicrographs), with slight or pronounced helical morphologies and multiple flagella at a single pole, and dividing forms. The latter were distinguishable from morphologically similar Ushaped (precoccoidal) bacteria in the decline phase by the presence of a division septum and flagellar filaments at each pole. In the early-decline phase of growth a high proportion of bacteria remained flagellate and had precoccoidal forms, whereas in the late-decline phase almost all bacteria were fully coccoidal, and usually devoid of flagella. The precoccoidal and coccoidal forms of $H$. pylori did not seem to be degenerative: both the bacterial cells and flagella, for instance, showed no obvious signs of the disintegration that occurs on exposure to bismuth and antibiotics (Armstrong et al., 1987; Nilius et al., 1993). 

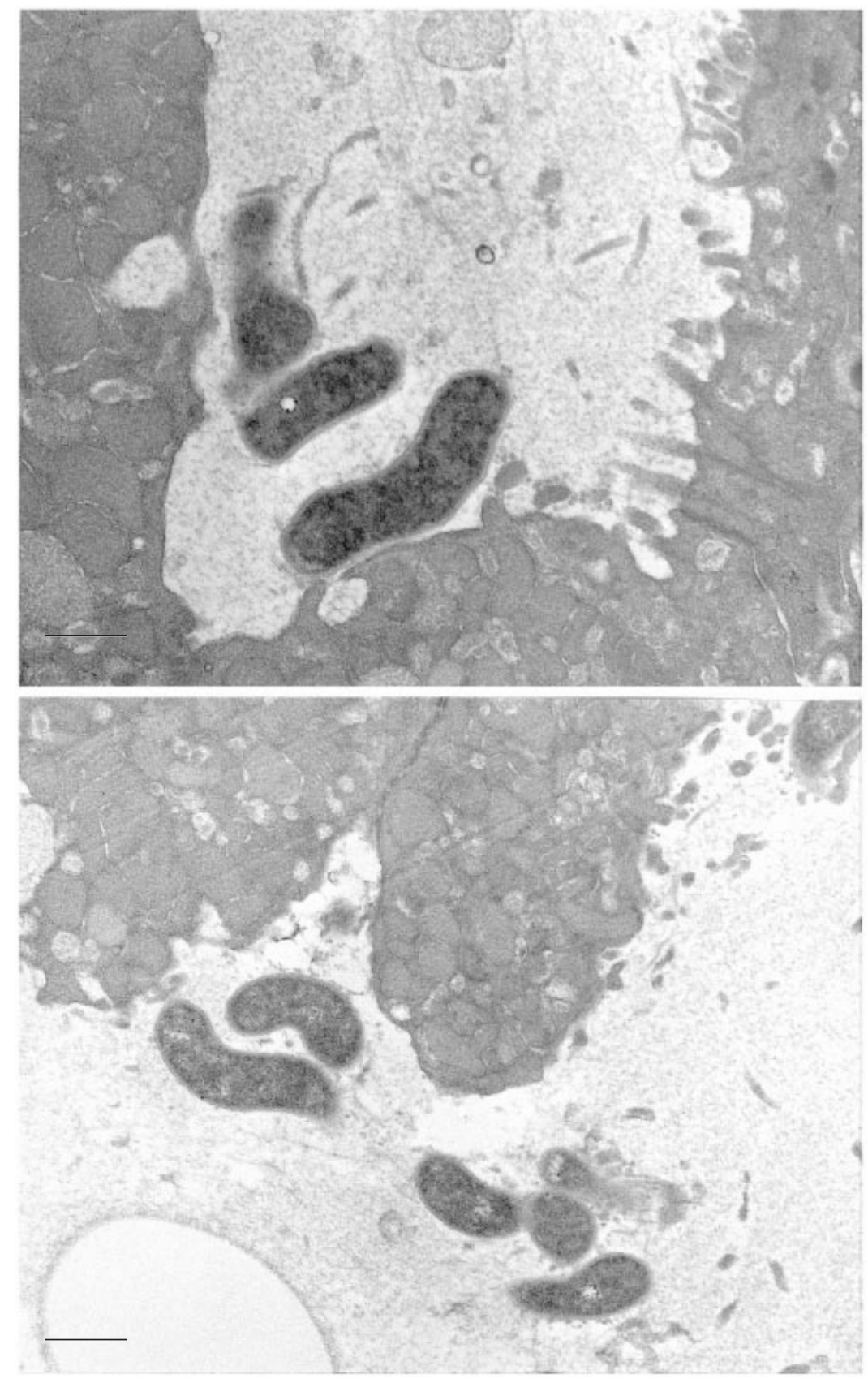

Fig. 5. Electron micrographs of the luminal surface of the gastric antrum in patients with non-autoimmune gastritis. H. pylori with helical morphology is located in the mucus layer close to the epithelial surface. Bars, $166 \mathrm{~nm}$.

\section{Morphologies of $\boldsymbol{H}$. pylori in antral biopsies}

Morphologies of H. pylori in antral mucosa under the transmission electron microscope are shown in Fig. 5. Non-dividing bacteria with helical morphologies predominated, and were located most frequently within the mucus layer close to the epithelial surface.

\section{DISCUSSION}

In this study we explored the relationship between $H$. pylori motility, morphology and phase of growth in batch and continuous culture systems, with the aim of further clarifying how bacterial motility and the different morphological forms of $H$. pylori influence gastric colonization and pathology.

All the H. pylori isolates investigated were highly motile when in exponential and stationary phases of growth, consistent with motility being a colonization factor for the bacterium. Motilities of $H$. pylori from patients with duodenal ulcer or non-ulcer dyspepsia were not found to be significantly different, however, when bacteria were in the same phase of growth, nor could the H. pylori isolates investigated, irrespective of source, be divided into two populations with significantly different motilities when in the same phase of growth. These latter findings are consistent with those from an earlier study (Worku et al., 1999), in which we showed that the 
motilities of $H$. pylori (in exponential phase) from patients with duodenal ulcer or non-ulcer dyspepsia were not significantly different in viscous media, at viscosities equivalent to those within the gastric mucus layer. Collectively these are potentially important observations, since they argue that an inherent difference in motility between strains is unlikely to be the determinant of $H$. pylori pathology or, for instance, the greater density of epithelial colonization in the antrum of patients with duodenal ulcer, when compared to those with non-ulcer dyspepsia (Khulusi et al., 1995).

$H$. pylori was found to exhibit highest motility when in late-exponential and early-stationary phases of growth. This observation mirrored our experience with other mucophiles (Campylobacter jejuni, Escherichia coli and Pseudomonas aeruginosa; unpublished observations), and accords with earlier work by other investigators (Kodaka et al., 1982; Macnab, 1996). The onset of $H$. pylori motility coincided with the appearance in the cultures of large numbers of non-dividing bacilli having helical morphologies and multiple polar flagella. Subsequent loss of motility after the bacteria entered the decline phase of growth coincided with the loss of this distinctive morphology [presumably from autohydrolysis of carbohydrate and peptide bonds in the peptidoglycan network (Baker \& Park, 1975; Thwaites \& Mendelson, 1991; Van Heijenoort, 1996)], and the appearance of flagellate precoccoidal, then aflagellate coccoidal forms.

Our data also confirm that the age of a batch culture can have a dramatic effect on flagellation, and support the view of Kodaka et al. (1982) and Josenhans et al. (1995a) that optimal flagellar development occurs when bacteria are in the exponential phase of growth. Loss of flagella from $H$. pylori in the late-decline phase of growth may be a further manifestation of the stress-induced autohydrolysis that releases surface proteins from the bacterial cell (Phadnis et al., 1996).

We are uncertain of the reasons for the poor motility of $H$. pylori in late-lag and early-exponential phases of growth, particularly as non-dividing flagellated bacteria in lag and exponential growth phases were morphologically indistinguishable. However, (i) the strong relationship that exists between bacterial motility and flagellin expression (Josenhans et al., 1995a) when $H$. pylori is in the exponential or stationary phase of growth (development of high bacterial motility in mid/lateexponential phase, for instance, coincides with a 10-20fold increase in expression of FlaA and FlaB subunits), and (ii) the dependence of full H. pylori motility on the presence of both flagellin subunits (Josenhans et al., 1995b) suggest that the cause is functional, and due to incomplete production of one or both flagellins. Such a deficiency, moreover, would not necessarily alter flagellar morphology (Josenhans et al., 1995b).

\section{Implications for gastric colonization}

The interrelationship between bacterial motility, morphology and phase of growth revealed by our in vitro experiments suggests that $H$. pylori in vivo with helical forms are likely to be highly motile and, therefore, suited to colonization of the gastric mucus layer. In contrast, the poorly motile precoccoidal or coccoidal form of $H$. pylori ought to be quickly cleared from the mucus environment. If these latter morphological forms are viable, then this characteristic should better fit them for a role in transmission of the infection.

The present study also provides a useful insight into the likely state of a typical population of $H$. pylori within the antral mucus layer. Most of the H. pylori colonizing the gastric antrum are to be found within the mucus environment (Terada et al., 1993; Thomsen et al., 1990) and [as we and other investigators (Buck et al., 1986; Hazell et al., 1986; Megraud, 1989) have shown] invariably possess helical morphologies. This observation, in conjunction with results from our in vitro studies of bacterial motility and morphology, and the dependence of gastric colonization on bacterial motility (Eaton et al., 1989, 1992), lead us to conclude that the typical $H$. pylori population within the antral mucus layer is in a state of continuous (exponential phase) growth.

To maintain a bacterial population in continuous growth the nutrient supply must at all times exceed that required by the bacteria (Duguid et al., 1978). H. pylori in the human stomach should attain this theoretical condition because the bacteria inhabit the gastric mucous barrier, a microenvironment whose physiological properties (Sidebotham \& Baron, 1994) will cause it to function in the manner of a chemostat. The nutrient supply to H. pylori within the mucous barrier is plasma, which transudes from damaged microcapillaries within the mucosa (Sidebotham et al., 1995). Although the supply of plasma is finite, it should be possible to keep it in excess of requirement because effective clearance mechanisms constantly limit the size of the bacterial population. These mechanisms include the secretion of abnormally viscous mucus (Curt \& Pringle, 1969; Markesich et al., 1995), which entraps and removes bacteria from the epithelial surface, and mucus erosion and the ' washout' effect of acid secretion, which displace bacteria into the gastric lumen. The greater susceptibility of $H$. pylori cells with inherently poor motility to clearance from the mucous barrier by these mechanisms will also ensure that bacteria in the exponential phase of growth are preferentially retained within the antral mucus layer.

\section{ACKNOWLEDGEMENTS}

We wish to thank Abbott Laboratories and the University of London for their gifts of equipment used in this work. We are indebted to Suresh Ladva for technical expertise in transmission electron microscopy.

\section{REFERENCES}

Andersen, A. P., Elliott, D. A., Lawson, M., Barland, P., Hatcher, V. B. \& Puszkin, E. G. (1997). Growth and morphological transformations of Helicobacter pylori in broth media. J Clin Microbiol 35, 2918-2922. 
Armstrong, J. A., Wee, S. H., Goodwin, C. S. \& Wilson, D. H. (1987). Response of Campylobacter pyloridis (Helicobacter pylori) to antibiotics, bismuth and an acid-reducing agent in vitro - an ultrastructural study. J Med Microbiol 24, 343-350.

Baker, D. A. \& Park, R. W. A. (1975). Changes in morphology and cell wall structure that occur during growth of Vibrio sp. NCTC4716 in batch culture. J Gen Microbiol 86, 12-18.

Baron, J. H. (1993). The ageing stomach. In Basic and Clinical Aspects of Helicobacter pylori, pp. 48-53. Edited by G. Gasbarrini \& S. Pretolani. Heidelberg: Springer.

Benaissa, M., Babin, P., Quellard, N., Pezennec, L., Cenatiempo, Y. \& Fauchere, J. L. (1996). Changes in Helicobacter pylori ultrastructure and antigens during conversion from the bacillary to the coccoid form. Infect Immun 64, 2331-2335.

Bode, G., Malfertheiner, P. \& Ditschuneit, H. (1991). Coccoid forms of $H$. pylori are viable. Ital J Gastroenterol 23 (suppl. 2) 35-36.

Buck, G. E., Gourley, W. K., Lee, W. K., Subramanyam, K., Latimer, J. M. \& Di Nuzzo, A. R. (1986). Relation of Campylobacter (Helicobacter) pylori to gastritis and peptic ulcer. J Infect Dis $\mathbf{1 5 3}$, 664-669.

Caselli, M., Aleotti, A., Boldrini, P., Ruina, M. \& Alvisi, V. (1993). Ultrastructural patterns of Helicobacter pylori. Gut 34, 1507-1509.

Catrenich, C. E. \& Makin, K. M. (1991). Characterisation of the morphologic conversion of Helicobacter pylori from bacillary to coccoid forms. Scand J Gastroenterol 26, (suppl. 181) 58-64.

Cellini, L., Allocati, N., Di Campli, E. \& Dainelli, B. (1994). Helicobacter pylori: a fickle germ. Microbiol Immunol 38, 25-30.

Chan, W. Y., Hui, P. K., Leung, K. M., Chow, J., Kwok, F. \& Ny, C. S. (1994). Coccoid forms of Helicobacter pylori in the human stomach. Am J Clin Pathol 102, 503-507.

Curt, J. R. N. \& Pringle, R. (1969). Viscosity of gastric mucus in duodenal ulceration. Gut 10, 931-934.

Duguid, J. P., Marmion, B. P. \& Swain, R. H. A. (editors) (1978). Growth and nutrition of bacteria. In Medical Microbiology, 13th edn, vol. 1. Microbial Infections, pp. 31-42. Edinburgh : Churchill Livingstone.

Eaton, K. A., Morgan, D. R. \& Krakowka, S. (1989). Virulence factors for Campylobacter (Helicobacter) pylori in gnotobiotic piglets. Infect Immun 57, 1119-1125.

Eaton, K. A., Morgan, D. R. \& Krakowka, S. (1992). Motility of Helicobacter pylori and virulence for gnotobiotic piglets. J Med Microbiol 37, 123-127.

Haschemyer, R. H. \& Meyers, R. J. (1972). Negative staining. In Principles and Techniques of Electron Microscopy, vol. 2, pp. 101-143. Edited by M. A. Hayat. New York: Van Nostrand Reinhold.

Hazell, S., Lee, A., Brady, L. \& Hennessy, W. (1986). Campylobacter pyloridis (Helicobacter pylori) and gastritis: association with intercellular spaces and adaptation to an environment of mucus as important factors in colonization of the gastric epithelium. $J$ Infect Dis 153, 658-663.

Hessey, S. J., Spencer, J., Wyatt, J. I., Sobala, G., Rathbone, B. J., Axon, A. T. R. \& Dixon, M. F. (1990). Bacterial adhesion and disease activity in Helicobacter-associated chronic gastritis. Gut 31, 134-138.

Hudson, M. J. \& Newell, D. G. (1989). Continuous culture of Campylobacter (Helicobacter) pylori. In Gastroduodenal Pathology and Campylobacter (Helicobacter) pylori, pp. 11-15. Edited by F. Megraud \& H. Lamouliatte. Amsterdam: Elsevier Science.
Janas, B., Czkwianianc, E., Bak-Romaniszyn, L., Bartel, H., Tosik, D. \& Planeta-Malecka, L. (1995). Electromicroscopic study of association between coccoid forms of Helicobacter pylori and gastric epithelial cells. Am J Gastroenterol 90, 1829-1833.

Jones, D. M. \& Curry, A. (1990). The genesis of coccoid forms of Helicobacter pylori. In Helicobacter pylori, Gastritis and Peptic Ulcer, pp. 29-37. Edited by P. Malfertheiner \& P. Ditschuneit. Berlin \& Heidelberg: Springer.

Josenhans, C., Labigne, A. \& Suerbaum, S. (1995a). Reporter gene analyses show that expression of both Helicobacter pylori flagellins is dependent on the growth phase. Gut 37, (suppl. 3), A62.

Josenhans, C., Labigne, A. \& Suerbaum, S. (1995b). Comparative ultrastructural and functional studies of Helicobacter pylori and Helicobacter mustelae flagellin mutants: both flagellin subunits FlaA and FlaB are necessary for full motility in Helicobacter species. J Bacteriol 177, 3010-3020.

Khulusi, S., Mendall, M. A., Patel, P., Levy, J., Badve, S. \& Northfield, T. C. (1995). Helicobacter pylori infection density and gastric inflammation in duodenal ulcer and non-ulcer subjects. Gut 37, 319-324.

Kodaka, H., Armfield, A. Y., Lombard, G. L. \& Dowell, V. R. (1982). Practical procedure for demonstrating bacterial flagella. $J$ Clin Microbiol 16, 948-952.

Kusters, J. G., Gerrits, M. M., Van Strijp, J. A. G. \& Vandenbroucke-Grauls, C. M. J. E. (1997). Coccoid forms of Helicobacter pylori are the morphologic manifestation of cell death. Infect Immun 65, 3672-3679.

Macnab, R. M. (1996). Flagella and motility. In Escherichia coli and Salmonella: Cellular and Molecular Biology, 2nd edn, vol. 1, pp. 123-145. Edited by F. C. Neidhardt and others. Washington, DC: American Society for Microbiology.

Mai, U., Geis, G., Leying, H., Ruhl, G. \& Opferkuch, W. (1989). Dimorphism of Campylobacter (Helicobacter) pylori. In Gastroduodenal Pathology and Campylobacter (Helicobacter) pylori, pp. 29-33. Edited by F. Megraud \& H. Lamouliatte. Amsterdam: Elsevier Science.

Markesich, D. C., Anand, B. S., Lew, G. M. \& Graham, D. Y. (1995). Helicobacter pylori infection does not reduce the viscosity of human gastric mucus gel. Gut 36, 327-329.

Megraud, F. (1989). Microbiological characteristics of Campylobacter (Helicobacter) pylori. Eur J Gastroenterol Hepatol 1, 5-12.

Miles, A. A., Misra, S. S. \& Irwin, J. O. (1938). The estimation of the bactericidal power of blood. J Hyg 38, 732-748.

Moshkowitz, M., Gorea, A., Arber, N., Konikoff, F., Berger, S. \& Gilat, T. (1994). Morphological transformation of Helicobacter pylori during prolonged incubation: association with decreased acid resistance. J Clin Pathol 47, 172-174.

Nilius, M., Strohle, A., Bode, G. \& Malfertheiner, P. (1993). Coccoid-like forms of Helicobacter pylori. Enzyme activity and antigenicity. Zentbl Bakteriol 280, 259-272.

Noach, L. A., Rolf, T. M. \& Tytgat, G. N. J. (1994). Electron microscopic study of association between Helicobacter pylori and gastric and duodenal mucosa. J Clin Pathol 47, 699-704.

Nomura, A., Stemmermann, G. N., Chyou, P. H., Perez-Perez, G. I. \& Blaser, M. J. (1994). Helicobacter pylori infection and the risk for duodenal and gastric ulceration. Ann Intern Med 120, 977-981.

O'Connor, F., Buckley, M. \& O'Morain, C. (1996). Helicobacter pylori: the cancer link. J R Soc Med 89, 674-678. 
Phadnis, S. H., Parlow, M. H., Levy, M., Ilver, D., Caulkins, C. M., Connors, J. B. \& Dunn, B. E. (1996). Surface localization of Helicobacter pylori urease and a heat shock protein homolog requires bacterial autolysis. Infect Immun 64, 905-912.

Sidebotham, R. L. \& Baron, J. H. (1994). Franklin Hollander: the two component mucous barrier. Gastroenterol Int 7, 135-140.

Sidebotham, R. L., Batten, J. J., Harris, A. W. \& Baron, J. H. (1995). Helicobacter pylori and the gastrin link. Gastroenterol Int $\mathbf{8}$, 162-166.

Terada, S., Negayama, K. \& Kawanishi, K. (1993). Neutrophil migration into the mucous layer in Helicobacter pylori-associated gastritis. Eur J Gastroenterol Hepatol 5 (suppl. 1), S45-S49.

Thomsen, L. L., Gavin, J. B. \& Tasman-Jones, C. (1990). Relation of Helicobacter pylori to the human gastric mucosa in chronic gastritis of the antrum. Gut 31, 1230-1236.
Thwaites, J. J. \& Mendelson, N. H. (1991). Mechanical behaviour of bacterial cell walls. Adv Microb Physiol 32, 173-222.

Van Heijenoort, J. (1996). Murein synthesis. In Escherichia coli and Salmonella: Cellular and Molecular Biology, 2nd edn, vol. 1, pp. 1025-1034. Edited by F. C. Neidhardt and others. Washington, DC: American Society for Microbiology.

Worku, M. L., Sidebotham, R. L., Baron, J. H., Misiewicz, J. J., Logan, R. P. H., Keshavarz, T. \& Karim, Q. N. (1999). Motility of Helicobacter pylori in a viscous environment. Eur J Gastroenterol Hepatol 11, 1-8.

Xia, H. X., English, L., Keane, C. T. \& O'Morain, C. A. (1993). Enhanced cultivation of Helicobacter pylori in liquid media. J Clin Pathol 46, 750-753.

Received 18 February 1999; revised 28 May 1999; accepted 1 June 1999. 